\title{
Determination of Trace Elements in Fluoropolymers after Microwave-Induced Combustion
}

\author{
Erico M. M. Flores, ${ }^{* \dagger}$ Edson I. Muller, ${ }^{\dagger}$ Fabio A. Duarte, ${ }^{\ddagger}$ Patricia Grinberg, ${ }^{\S}$ and Ralph E. Sturgeon ${ }^{\S}$ \\ ${ }^{\dagger}$ Departamento de Química, Universidade Federal de Santa Maria, 97105-900 Santa Maria, RS, Brazil \\ \#Escola de Química e Alimentos, Universidade Federal do Rio Grande, 96201-900 Rio Grande, RS, Brazil \\ ${ }^{\S}$ National Research Council Canada, Ottawa, Ontario, CAN K1A 0R6, Canada
}

ABSTRACT: An effective approach to the digestion of fluoropolymers for the determination of $\mathrm{Ag}, \mathrm{Ca}, \mathrm{Cd}, \mathrm{Co}, \mathrm{Cr}$, $\mathrm{Cu}, \mathrm{Fe}, \mathrm{K}, \mathrm{Mg}, \mathrm{Mn}$, and $\mathrm{Ni}$ impurities has been developed using microwave-induced combustion (MIC) in closed quartz vessels pressurized with oxygen. Samples that were examined included the following: polytetrafluorethylene (PTFE); polytetrafluoroethylene with an additional modifier, perfluoropropylvinylether (PTFE-TFM); and fluorinated ethylene propylene (FEP). A quartz device was used as a sample holder, and

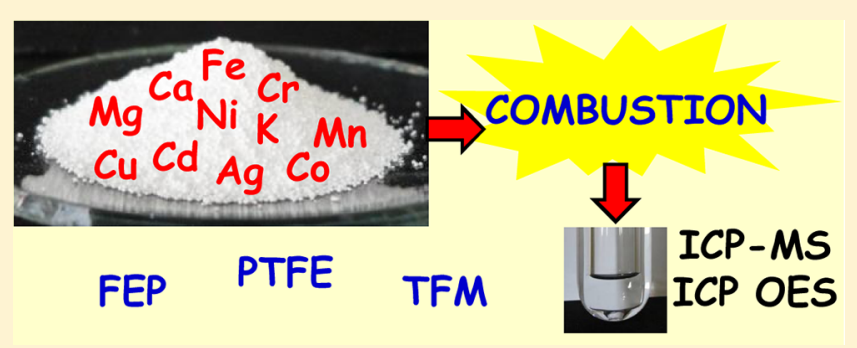
the influence of the absorber solution was evaluated. Determination of trace elements was performed by inductively coupled plasma-optical emission and mass spectrometry. Neutron activation analysis (NAA) was used for validation purposes. Results were also compared to those obtained using microwave-assisted acid extraction in high-pressure closed systems. Dilute nitric acid $\left(5 \mathrm{~mol} \mathrm{~L}^{-1}\right)$, which was selected as the absorbing medium, was used to reflux the sample for $5 \mathrm{~min}$ after the combustion. Using these conditions, agreement for all analytes was better than $98 \%$ when compared to values determined by NAA. The residual carbon content in the digests was lower than $1 \%$, illustrating the high efficiency of the method. Up to 8 samples could be digested within 30 min using MIC, providing a suitable throughput, taking into account the inertness of such samples.

$\mathrm{F}$ luoropolymers represent a rather specialized group of polymeric materials with large numbers of new types being continuously developed. Some are derivatives of the original polytetrafluoroethylene (PTFE), such as fluorinated ethylene propylene (FEP) and polytetrafluoroethylene with additional modifier, perfluoropropylvinylether (PTFE-TFM), etc. ${ }^{1,2}$ These compounds are used in numerous industrial applications, because of their favorable properties of high resistance to corrosive reagents, thermal stability, inertness, resistance to aging and low coefficient of friction. ${ }^{3}$ Fluoropolymers are widely used in chemical, automotive, aerospace, electrical, and electronic industries, medical devices, special packaging, communications, protective garments, and a variety of other industrial and consumer products. ${ }^{2}$ For some of these applications, i.e., the production of semiconductors, fluoropolymers must present high purity in order to ensure their performance, especially with respect to their trace element content. $^{2,4,5}$

The expanded use of fluoropolymers as raw materials in industrial processes requires the development of rapid and accurate methods of analysis having limits of detection (LOD) suitable for the determination of contaminants at low levels, several of which have been described for the determination of trace elements in polyethylene, ${ }^{6}$ acrylonitrile butadiene styrene, ${ }^{6}$ polyethyleneterephthalate, ${ }^{7}$ polystyrene, ${ }^{8}$ and poly(vinyl chloride). ${ }^{8}$ However, despite numerous quality control requirements, only a few studies have appeared related to trace elements in fluoropolymers. ${ }^{9-13}$ These materials are exceptionally inert, extremely difficult to solubilize, and generally require complex and time-consuming sample preparation procedures. Previous research efforts for the determination of metallic contaminants in fluoropolymers have been based on extraction $^{9,10}$ and combustion methods. ${ }^{11}$ Combustion systems operating at atmospheric pressure using oxygen and quartz tubes heated to $600{ }^{\circ} \mathrm{C}$ have been used for digestion of PTFE with subsequent determination of metallic impurities by electrothermal atomic absorption spectrometry. ${ }^{12}$ However, only a portion of $\sim 200 \mathrm{mg}$ of such test samples was used and the residue on the quartz boat had to be digested with nitric acid after the combustion step. Moreover, to avoid contamination, each boat was used only once. ${ }^{12}$

To obviate the difficulties involved in digestion of fluoropolymers, solid sampling-electrothermal vaporizationinductively coupled plasma mass spectrometry has been used for multielement analysis of these materials. This method exhibits useful features, such as low detection limits ( $\mathrm{ng} \mathrm{g}^{-1}$ range) with calibration performed using aqueous standard solutions for at least seven analytes $(\mathrm{Cr}, \mathrm{Cu}, \mathrm{Fe}, \mathrm{K}, \mathrm{Mn}, \mathrm{Pb}$, and $\mathrm{Zn})$. However, it is clear that this technique is not readily available in many laboratories and requires careful optimization

Received: October 8, 2012

Accepted: November 21, 2012

Published: November 21, 2012 
of operating conditions (e.g., isotope selection, temperature program, use of $\mathrm{Pd}$ as both chemical modifier and internal standard) to obtain suitable results. ${ }^{13}$

Microwave-assisted wet digestion (MAD) in closed vessels has been extensively used for many matrices in view of its high digestion efficiency for most samples, relatively low reagent consumption, and reduced risk of losses and contamination, in comparison to conventional digestion procedures. ${ }^{14}$ However, MAD suffers several limitations for digestion of polymers and, particularly fluoropolymers, because of the inertness of such materials. ${ }^{15}$ A very effective system that was proposed for the digestion of a variety of organic samples and successfully applied for fluoropolymers digestion is the cool plasma asher. This system, which is based on a highly reactive oxygen plasma generated in situ, allows complete digestion of fluoropolymers (0.5 g) within $\sim 3 \mathrm{~h}^{15}$

As an alternative to these methods, mainly to MAD, combustion techniques are more effective for complete matrix destruction due to the high temperature achieved (more than $\left.1000{ }^{\circ} \mathrm{C}\right)$. Combustion methods utilizing closed vessels (combustion bomb and oxygen flask) allow the complete conversion of carbon and hydrogen to carbon dioxide and water, thus representing a convenient and effective means of obtaining solubilized samples with minimum residual organic matrix while avoiding some difficulties for subsequent analyte determinations. ${ }^{16} \mathrm{~A}$ digestion method combining the advantages of classical combustion systems with those using closed systems heated by microwave radiation was recently proposed. ${ }^{17}$ This microwave-induced combustion (MIC) method has been used for the digestion of organic samples in closed quartz vessels pressurized with oxygen and ignited by the application of microwave radiation. ${ }^{18-28}$ In this system, the sample is placed on a small quartz holder positioned inside a high-purity quartz vessel. Vessels are pressurized with 15-20 bar of oxygen, and the sample was combusted following the application of microwave radiation. Contrary to other combustion methods, MIC conveniently incorporates an optional reflux step that significantly improves analyte recovery. Using MIC, the consumption of concentrated acids is minimized; moreover, dilute acids can be used for most analytes, generating enhanced limits of detection with a lower generation of waste. ${ }^{16}$

In the present work, MIC is proposed, for the first time, for the digestion of fluoropolymers, and its feasibility is demonstrated by the determination of $\mathrm{Ag}, \mathrm{Cd}, \mathrm{Co}, \mathrm{Cr}, \mathrm{Cu}$, $\mathrm{Mn}$, and $\mathrm{Ni}$ by inductively coupled plasma-mass spectrometry (ICP-MS). Other elements, present in higher concentrations ( $\mathrm{Ca}, \mathrm{Fe}, \mathrm{K}$, and $\mathrm{Mg}$ ), were determined by inductively coupled plasma-optical emission spectrometry (ICP-OES). Solutions of nitric acid $\left(0.5-14 \mathrm{~mol} \mathrm{~L}^{-1}\right)$ were evaluated as absorber solutions during a subsequent reflux step. Other experimental parameters were optimized, including sample mass and $\mathrm{O}_{2}$ pressure. Because certified reference materials (CRMs) for fluoropolymers are not available, neutron activation analysis (NAA) served to verify the accuracy of the results. Recovery tests were also performed on all analytes. The efficiency of the oxidation process was evaluated by the determination of the residual carbon content (RCC) in all digests.

\section{EXPERIMENTAL SECTION}

Instrumentation. Samples of fluoropolymers were decomposed by MIC using a Multiwave 3000 microwave sample preparation system (Anton Paar, Graz, Austria). In this work, combustion was performed using two equipment systems controlled by two different versions of software (version v2.02 or v1.27-Synt, permitting operation with maximum rates of pressure rise of 0.8 or $3 \mathrm{bar} \mathrm{s}^{-1}$, respectively). The system was equipped with up to eight high-pressure quartz vessels having an internal volume of $80 \mathrm{~mL}$ (maximum pressure and temperature of 80 bar and $280{ }^{\circ} \mathrm{C}$, respectively). Quartz holders were used to position the pelletized sample in each vessel. Pressure and temperature were monitored by the original equipment sensors. The temperature achieved during combustion was determined using an optical pyrometer (Ultimax Infrared Thermometer, Ircon, Niles, IL).

An inductively coupled plasma mass spectrometer (PerkinElmer Sciex, Model Elan DRC II, Thornhill, Canada), equipped with a concentric nebullizer (Meinhard Associates, Golden, CO, USA), a cyclonic spray chamber (Glass Expansion, Inc., West Melbourne, Australia) and a quartz torch with a quartz injector tube ( $2 \mathrm{~mm}$ i.d.), was used for quantitation of $\mathrm{Ag}, \mathrm{Cd}$, $\mathrm{Co}, \mathrm{Cr}, \mathrm{Cu}, \mathrm{Mn}$, and $\mathrm{Ni}$ in the digests. Elements present at higher concentration in the samples or those suffering isobaric or polyatomic interferences in ICP-MS $(\mathrm{Ca}, \mathrm{Fe}, \mathrm{K}, \mathrm{Mg}$ ) were determined using an inductively coupled plasma-optical emission spectrometer (Varian, Model 720-ES). The operating conditions for ICP-MS and ICP-OES spectrometers are summarized in Table 1. For the determination of RCC, an

\section{Table 1. ICP-MS Operating Parameters}

\begin{tabular}{|c|c|c|}
\hline parameter & ICP-MS & ICP-OES \\
\hline RF power & $1300 \mathrm{~W}$ & $1200 \mathrm{~W}$ \\
\hline plasma gas flow rate & $15.0 \mathrm{~L} \mathrm{~min}^{-1}$ & $15.0 \mathrm{~L} \mathrm{~min}^{-1}$ \\
\hline auxiliary gas flow rate & $1.20 \mathrm{~L} \mathrm{~min}^{-1}$ & $1.50 \mathrm{~L} \mathrm{~min}^{-1}$ \\
\hline nebullizer gas flow rate & $1.10 \mathrm{~L} \mathrm{~min}^{-1}$ & $0.80 \mathrm{~L} \mathrm{~min}^{-1}$ \\
\hline spray chamber & cyclonic & cyclonic \\
\hline nebullizer & concentric & concentric \\
\hline sampler and skimmer cones & Pt & \\
\hline ion lens & auto lens on & \\
\hline dwell time (ms) & $3 \mathrm{~ms}$ & \\
\hline \multirow[t]{7}{*}{ isotopes $(m / z)$} & ${ }^{107} \mathrm{Ag}$ & \\
\hline & ${ }^{111} \mathrm{Cd}$ & \\
\hline & ${ }^{53} \mathrm{Cr}$ & \\
\hline & ${ }^{63} \mathrm{Cu}$ & \\
\hline & ${ }^{55} \mathrm{Mn}$ & \\
\hline & ${ }^{60} \mathrm{Ni}$ & \\
\hline & ${ }^{66} \mathrm{Zn}$ & \\
\hline \multirow[t]{4}{*}{ wavelength (nm) } & & Ca, $396.847 \mathrm{~nm}$ \\
\hline & & $\mathrm{Fe}, 238.204 \mathrm{~nm}$ \\
\hline & & $\mathrm{K}, 766.491 \mathrm{~nm}$ \\
\hline & & $\mathrm{Mg}, 285.213 \mathrm{~nm}$ \\
\hline
\end{tabular}

axial view ICP-OES (Model Spectro Ciros CCD, Spectro Analytical Instruments, Kleve, Germany) equipped with a cross-flow nebullizer coupled to a Scott double-pass spray chamber was used; the C(I) emission line at $193.091 \mathrm{~nm}$ was monitored. ${ }^{17}$ A potentiometer fitted with an ion-selective electrode (Model $781 \mathrm{pH} /$ Ion Meter, Metrohm, Herisau, Switzerland) was used for determination of fluoride in digests obtained after MIC of the fluoropolymer samples.

NAA was performed at the Instituto de Pesquisas Energéticas e Nucleares (São Paulo, Brazil). Sample masses ranging from $50 \mathrm{mg}$ to $300 \mathrm{mg}$ were irradiated using a neutron flux of $3 \times$ $10^{12} \mathrm{n} \mathrm{cm}^{-2} \mathrm{~s}^{-1}$ for $30 \mathrm{~s}(\mathrm{Cu}$ and $\mathrm{Mn})$ or $8 \mathrm{~h}(\mathrm{Ag}, \mathrm{Co}, \mathrm{Cr}, \mathrm{Fe}$, $\mathrm{K}$, and $\mathrm{Mg}$ ). Detection of $\gamma$ radiation was achieved using a $\mathrm{Ge}$ 
detector (Canberra, GX 2020) having a resolution of $1.70 \mathrm{keV}$ at the $1332.49 \mathrm{keV}$ peak of ${ }^{60} \mathrm{Co}$.

Reagents and Samples. All reagents used in this work were of analytical grade. Distilled, deionized water used to prepare all reagents and standard solutions was further purified using a Milli-Q system (Millipore Corp., Bedford, MA, USA). Concentrated $\mathrm{HNO}_{3}$ (65\%) and $\mathrm{HCl}$ (37\%) (Merck, Darmstadt, Germany) were purified using a sub-boiling distillation system (Milestone, Model Duopur, Bergamo, Italy). Working analytical solutions for each element were prepared by serial dilution of $1000 \mathrm{mg} \mathrm{L}^{-1}$ stock reference solutions. Absorber solutions were prepared by dilution of concentrated nitric acid with purified water. A solution of ammonium nitrate $\left(6 \mathrm{~mol} \mathrm{~L}^{-1}\right)$ was used as an igniter for the MIC procedure and was prepared by dissolving the respective salt (Merck) in water.

Small disks of filter paper (15 mm diameter, $\sim 12 \mathrm{mg})$ with low ash content (Black Ribbon Ashless, Schleicher and Schuell, Dassel, Germany) were used as an aid for the combustion process. The disks were previously leached with $10 \%(\mathrm{v} / \mathrm{v})$ $\mathrm{HNO}_{3}$ for $20 \mathrm{~min}$ in an ultrasonic bath, further washed with water and dried in a Class 100 laminar bench (CSLH-12, Veco, Brazil). Cleaning of the digestion vessels and holders was undertaken by placing $6 \mathrm{~mL}$ of $14 \mathrm{~mol} \mathrm{~L}^{-1} \mathrm{HNO}_{3}$ into each and subjecting them to a program of to $1400 \mathrm{~W}$ for $10 \mathrm{~min}$ and $0 \mathrm{~W}$ for $20 \mathrm{~min}$ (cooling step) in the microwave oven. Glass and quartz materials were soaked in $10 \%(\mathrm{v} / \mathrm{v}) \mathrm{HNO}_{3}$ (Merck) for $24 \mathrm{~h}$ and thoroughly washed with water before use.

Three powdered commercial high-purity fluoropolymer samples (particle diameter of $<0.8 \mathrm{~mm}$ ) of PTFE-TFM (sample 1, polytetrafluoroethylene with an additional modifier, perfluoropropylvinylether), PTFE (sample 2, polytetrafluorethylene), and FEP (sample 3, fluorinated ethylene propylene) were used in this study. Fluoropolymers were pressed as pellets (diameter of $13 \mathrm{~mm}$ ) using a hydraulic press set at 5 tons per square inch (Specac, Orpington, U.K.). In order to evaluate potential contamination introduced by the pressing procedure, masses of 50,100,200, and $400 \mathrm{mg}$ of sample (sample with lower content of metals) were pressed and digested using MIC while monitoring $\mathrm{Cr}, \mathrm{Fe}$, and $\mathrm{Mn}$ (likely present in steel of the press parts) by ICP-OES and ICP-MS.

Microwave-Induced Combustion. Using the proposed MIC method, sample masses between 100 and $400 \mathrm{mg}$ were pressed and positioned together with the filter paper in the quartz holder of the MIC system. Quartz vessels were previously filled with $6 \mathrm{~mL}$ of absorber solution $(0.5,1.0,2.0$, 5.0, 7.0, 10, or $14 \mathrm{~mol} \mathrm{~L}^{-1} \mathrm{HNO}_{3}$ ). The holder containing the sample was placed into a quartz microwave vessel and ammonium nitrate $\left(50 \mu \mathrm{L}\right.$ of $6 \mathrm{~mol} \mathrm{~L}^{-1}$ solution $)$ was immediately added to the paper. After closing the vessels and capping the rotor, vessels were slowly pressurized with oxygen to $20 \mathrm{bar}$ over a period of $1 \mathrm{~min}$. A rotor containing up to eight quartz vessels was placed inside the microwave oven and subjected to the following MIC procedure: $1400 \mathrm{~W}$ for 1 or 10 min (if the optional reflux step was used) and $0 \mathrm{~W}$ for $20 \mathrm{~min}$ (cooling step). Depending on the microwave oven used, the maximum rate of rise of pressure was limited to 0.8 or $3 \mathrm{bar} \mathrm{s}^{-1}$ (for four or eight simultaneous combustions). Previous studies also demonstrated that the use of a reflux step allows better recoveries for determination of metals when compared to combustion without a reflux step. ${ }^{18-25}$ For the combustion step, the microwave power was set at $1400 \mathrm{~W}$ for $10 \mathrm{~min}$. Resultant solutions were diluted with water and transferred to
30-mL polypropylene vessels. After each run, holders were soaked in concentrated $\mathrm{HNO}_{3}$ for 10 min followed by rinsing with water. After suitable dilution, $\mathrm{Ag}, \mathrm{Cd}, \mathrm{Co}, \mathrm{Cr}, \mathrm{Cu}, \mathrm{Mn}$, and $\mathrm{Ni}$ were quantitated by ICP-MS and $\mathrm{C}, \mathrm{Ca}, \mathrm{Fe}, \mathrm{K}$ and $\mathrm{Mg}$ were quantitated by ICP-OES.

An extraction procedure was also performed using conventional microwave-assisted digestion employing closed highpressure vessels. Initially, $500 \mathrm{mg}$ of sample was weighed into the vessel and $6 \mathrm{~mL}$ of concentrated $\mathrm{HNO}_{3}$ were added. Vessels were closed and heated to generate a maximum pressure of 80 bar by applying a 10-min ramp and 30-min hold time at $1400 \mathrm{~W}$ reaching a temperature of $230{ }^{\circ} \mathrm{C}$. After cooling, extracts were diluted to $30 \mathrm{~mL}$ with water, centrifuged and trace elements were determined by ICP-MS and ICP-OES. The different procedures used for analysis of fluoropolymers are shown in Figure 1.

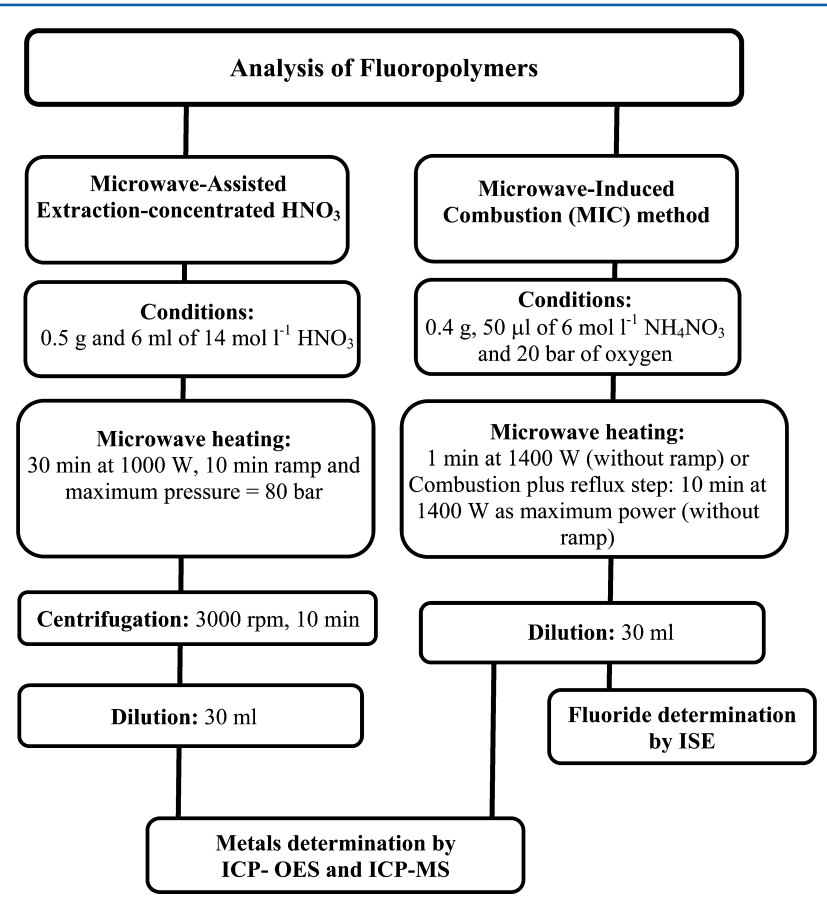

Figure 1. Different procedures used for the analysis of fluoropolymers.

In order to evaluate the residual fluoride after MIC, its concentration in the digests was determined using potentiometry with an ion-selective electrode (ISE) after suitable dilution with a total ionic strength adjustment buffer (TISAB). ${ }^{29}$

\section{RESULTS AND DISCUSSION}

Microwave-Assisted Extraction with Concentrated Nitric Acid. A procedure based on extraction using concentrated nitric acid in high-pressure closed vessels was initially investigated for recovery of trace elements. As expected, using this procedure, the samples remained visibly undigested, accompanied by a solid suspension. After centrifugation, the extracts were analyzed by ICP-MS and ICP-OES. Determination of $\mathrm{Ag}, \mathrm{Cd}, \mathrm{Co}, \mathrm{Cr}, \mathrm{Cu}, \mathrm{Mn}$, and $\mathrm{Ni}$ was carried out by ICP-MS, whereas $\mathrm{Ca}, \mathrm{Fe}, \mathrm{K}$, and $\mathrm{Mg}$, which are present in higher concentrations, were determined by ICP-OES. Results are shown in Table 2.

In general, $\mathrm{Ca}, \mathrm{Cr}, \mathrm{Fe}$, and $\mathrm{K}$ were present at relatively high concentrations in both samples; $\mathrm{Fe}$ was present at very high levels $\left(21500 \mathrm{ng} \mathrm{g}^{-1}\right)$ compared with other elements. Elevated 
Table 2. Results for Trace Element Analysis Following Microwave-Induced Combustion (MIC) ${ }^{a}$

\begin{tabular}{|c|c|c|c|c|c|c|}
\hline \multirow[b]{3}{*}{ element } & \multicolumn{6}{|c|}{ Concentration $\left(\mathrm{ng} \mathrm{g}^{-1}\right)$} \\
\hline & \multicolumn{2}{|c|}{ Sample 1} & \multicolumn{2}{|c|}{ Sample 2} & \multicolumn{2}{|c|}{ Sample 3} \\
\hline & MIC & extraction & MIC & extraction & MIC & extraction \\
\hline $\mathrm{Ag}$ & $<10$ & $<30$ & $<10$ & $<30$ & $<10$ & $<30$ \\
\hline $\mathrm{Ca}$ & $8200 \pm 1250$ & $4050 \pm 660$ & $3050 \pm 370$ & $1740 \pm 310$ & $6460 \pm 870$ & $4350 \pm 710$ \\
\hline $\mathrm{Cd}$ & $<10$ & $<30$ & $<10$ & $<30$ & $<10$ & $<30$ \\
\hline Co & $<10$ & $<40$ & $<10$ & $<40$ & $<10$ & $<40$ \\
\hline $\mathrm{Cr}$ & $2250 \pm 100$ & $2110 \pm 150$ & $50 \pm 14$ & $48 \pm 9$ & $1370 \pm 120$ & $1285 \pm 90$ \\
\hline $\mathrm{Cu}$ & $200 \pm 23$ & $67 \pm 16$ & $127 \pm 14$ & $51 \pm 8$ & $310 \pm 20$ & $138 \pm 45$ \\
\hline $\mathrm{Fe}$ & $21800 \pm 800$ & $21500 \pm 1200$ & $1630 \pm 350$ & $1540 \pm 330$ & $5180 \pm 420$ & $5230 \pm 370$ \\
\hline $\mathrm{K}$ & $5440 \pm 750$ & $1020 \pm 660$ & $590 \pm 170$ & $356 \pm 59$ & $6400 \pm 350$ & $5120 \pm 415$ \\
\hline $\mathrm{Mg}$ & $900 \pm 75$ & $500 \pm 110$ & $235 \pm 20$ & $127 \pm 18$ & $540 \pm 30$ & $390 \pm 45$ \\
\hline $\mathrm{Mn}$ & $150 \pm 10$ & $150 \pm 10$ & $47 \pm 6$ & $45 \pm 6$ & $90 \pm 8$ & $89 \pm 10$ \\
\hline $\mathrm{Ni}$ & $210 \pm 20$ & $220 \pm 20$ & $570 \pm 80$ & $490 \pm 75$ & $980 \pm 80$ & $920 \pm 60$ \\
\hline
\end{tabular}

${ }^{a}$ Mean \pm standard deviation $(n=3)$. NAA results $\left(\mathrm{ng} \mathrm{g}^{-1}\right)$ for sample 1: $\mathrm{Ag},<80 ; \mathrm{Co},<20 ; \mathrm{Cu},<440 ; \mathrm{Cr}, 2280 \pm 70 ; \mathrm{Fe}, 21250 \pm 950 ; \mathrm{K}, 5100 \pm$ $1050 ; \mathrm{Mg}, 880 \pm 80 ;$ and $\mathrm{Mn}, 145 \pm 5$.

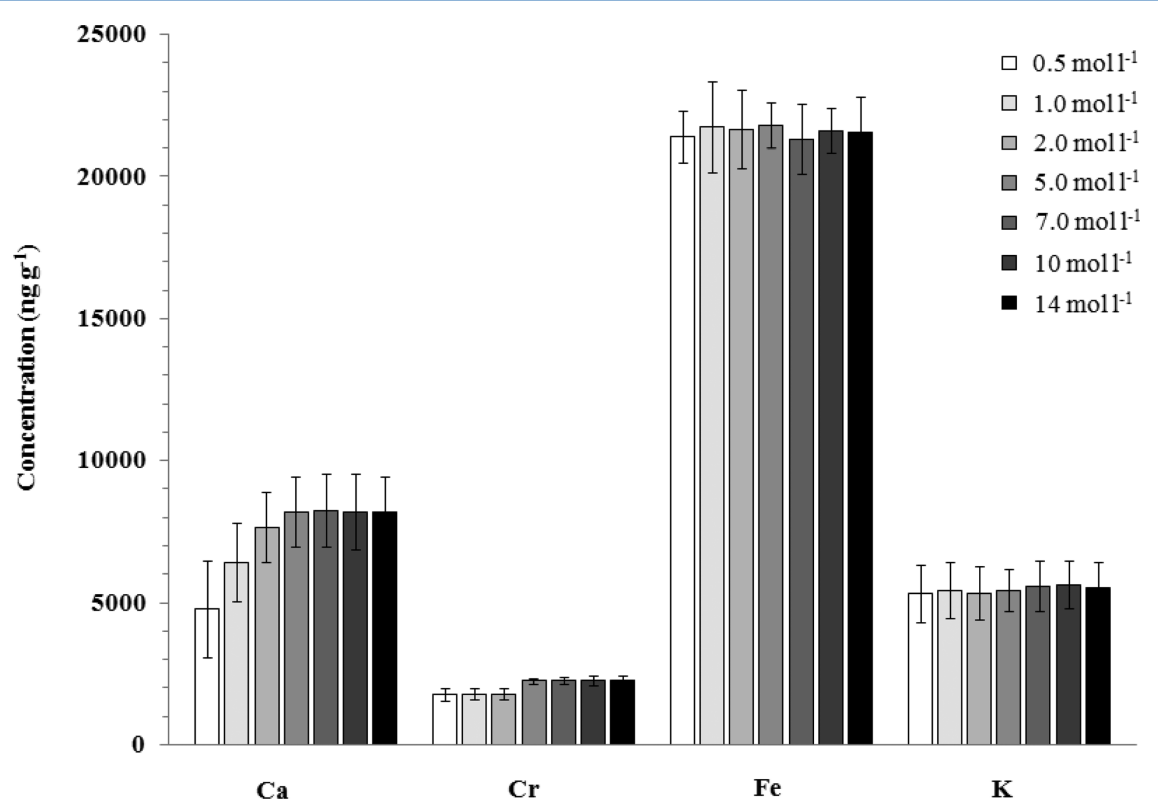

Figure 2. Influence of concentration of $\mathrm{HNO}_{3}$ as absorber solution using $\mathrm{MIC}$ (combined with reflux step) and subsequent determination of Ca, Cr, $\mathrm{Fe}$, and $\mathrm{K}$ in sample 1. Determination by ICP-MS and ICP-OES (error bars are the standard deviation, $n=3$ ).

levels of $\mathrm{Fe}$ and $\mathrm{Cr}$ were also evident from previous work in which different fluoropolymers were analyzed following extraction with nitric acid. ${ }^{30}$ These metals are frequent constituents of mechanical machines and reactors encountered during polymer synthesis and their elevated concentrations may reflect possible contamination from such surfaces. In the case of Ca (NAA data were not available), the relatively high concentration found could arise from the use of calcium salts as a nucleating agent for foaming and as an antiblocking additive. ${ }^{31,32}$ Good agreement ( $t$-test, 95\% confidence level) between NAA and extraction results was obtained only for $\mathrm{Cr}$, $\mathrm{Fe}$, and $\mathrm{Mn}$, suggesting that the experimental conditions were adequate for recovery of these elements. However, for $\mathrm{K}$ and $\mathrm{Mg}$, the agreement was not acceptable. Unfortunately, for Ag, $\mathrm{Co}$, and $\mathrm{Cu}$, the limits of detection achieved with NAA (i.e., 80, 23 , and $440 \mathrm{ng} \mathrm{g}^{-1}$, respectively) were inadequate to quantitate these elements and, as such, it was not possible to dispute the veracity of the data arising from the use of hot acid extraction (i.e., $<30 \mathrm{ng} \mathrm{g}^{-1}$ for $\mathrm{Ag}$, $<40 \mathrm{ng} \mathrm{g}^{-1}$ for $\mathrm{Co}$, and $67 \pm 16 \mathrm{ng} \mathrm{g}^{-1}$ for $\mathrm{Cu}$ ). For $\mathrm{Ca}, \mathrm{Cd}$, and $\mathrm{Ni}$, comparison was not possible because NAA values were not available. Therefore, extraction using concentrated nitric acid in closed vessels could only be considered feasible for $\mathrm{Cr}, \mathrm{Fe}$, and $\mathrm{Mn}$ and unsuitable for determination of the remaining trace elements in fluoropolymers.

Optimization of Microwave-Induced Combustion (MIC) Conditions. An initial study was performed in order to evaluate the characteristics of the MIC system, such as the maximum sample mass that can be accommodated and the maximum pressure achieved during combustion. For this purpose, pellets comprising different masses of sample 1 were prepared (100, 200, and $400 \mathrm{mg}$ ). Using $100 \mathrm{mg}$ of sample 1 , the maximum pressure generated was $\sim 26$ bar (the initial $\mathrm{O}_{2}$ pressure was $20 \mathrm{bar}$ ) and even using sample masses up to 400 $\mathrm{mg}$, the maximum pressure was $49 \mathrm{bar}$, or $\sim 61 \%$ of the maximum pressure recommended by the manufacturer for routine use of MAD ( $80 \mathrm{bar}$ ). After MIC, the absorber solution was completely clear and without visible particles. Therefore, because the procedure was considered safe for digestion up to 


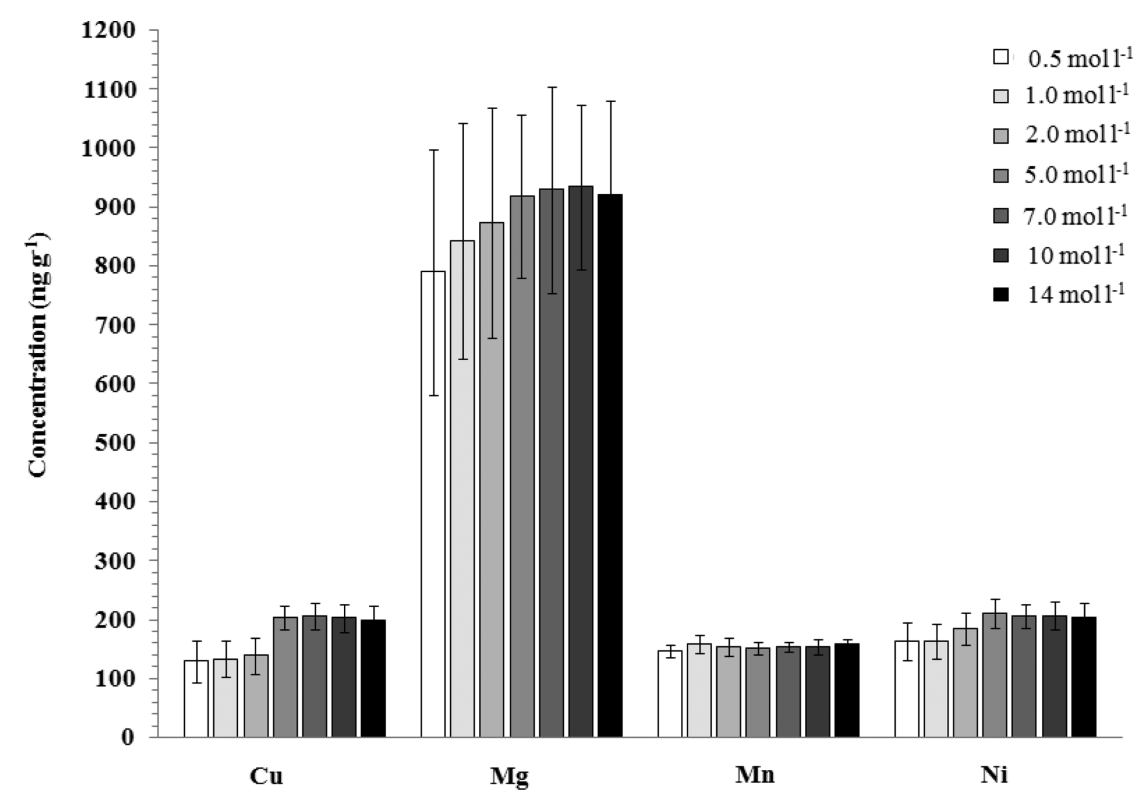

Figure 3. Influence of concentration of $\mathrm{HNO}_{3}$ as absorber solution using $\mathrm{MIC}$ (combined with reflux step) and subsequent determination of Cu, $\mathrm{Mg}, \mathrm{Mn}$, and $\mathrm{Ni}$ in sample 1. Determination by ICP-MS and ICP-OES (error bars are the standard deviation, $n=3$ ).

$400 \mathrm{mg}$, this test mass was selected as the maximum mass of sample pellet for further experiments.

An evaluation of possible contamination during the pressing step was additionally completed by the determination of $\mathrm{Cr}$, $\mathrm{Mn}$, and $\mathrm{Fe}$ in pellets prepared using masses of sample 2 ranging from $50 \mathrm{mg}$ to $400 \mathrm{mg}$. For $\mathrm{Cr}$ and $\mathrm{Mn}$, results obtained for pellets containing 50,100, and $200 \mathrm{mg}$ of sample were very close to the procedural blanks, while results obtained using 400-mg pellets showed good agreement with those obtained with NAA and microwave-assisted extraction procedures (neither use the pressing step). Results for iron obtained with different sample masses were in good agreement with those generated using microwave-assisted extraction. It may be concluded that contamination arising from the use of the press to prepare the pellets can be considered to be negligible.

Optimization of the Absorber Solution for Optimum Recovery with MIC. The selection of absorber solution, particularly for combustion methods, impacts optimal recoveries and, while dependent on the nature of the analyte, should be compatible with the selected determination technique. ${ }^{17}$ In general, concentrated acids are not required and dilute solutions can be used for most applications, thereby minimizing reagent consumption and its contribution to the procedural blank. Typically, nitric acid solutions are preferred due to their better compatibility with plasma conditions and because it is a convenient medium with which to keep analytes in solution.

The suitability of nitric acid as the absorber solution was evaluated by comparing results for solutions of $0.5,1.0,2.0,5.0$, 7.0, 10, and $14 \mathrm{~mol} \mathrm{~L}^{-1} \mathrm{HNO}_{3}$. Results are summarized in Figures 2 and 3. For some elements ( $\mathrm{Fe}, \mathrm{K}$, and $\mathrm{Mn}$ ), the recoveries were virtually independent of the absorber solution concentration, permitting a solution as dilute as $0.5 \mathrm{~mol} \mathrm{~L}^{-1}$ $\mathrm{HNO}_{3}$ to be used for their determination. Similar behavior was evident for $\mathrm{Cr}$, for which a recovery of $\sim 85 \%$ was found using 0.5-2 $\mathrm{mol} \mathrm{L}^{-1} \mathrm{HNO}_{3}$ as the absorbing medium. However, quantitative results were only obtained when using at least 5 mol L ${ }^{-1} \mathrm{HNO}_{3}$. For $\mathrm{Fe}$ and $\mathrm{Mn}$, the good agreement achieved using very dilute solutions of $\mathrm{HNO}_{3}$ for even conventional microwave-assisted extraction is likely an indication that these elements are present in these samples as surface contaminants arising from their contact with components of processing machinery (likely post-synthesis). In addition, for these elements, good agreement $(>98 \%)$ with the respective results by NAA is evident. Contrary to other studies wherein the use of more concentrated absorber solutions results in lower RSDs for $\mathrm{Fe}$ and $\mathrm{Mn}$, the RSD was practically independent of the concentration of absorber solution. ${ }^{25}$

For $\mathrm{Ca}, \mathrm{Cu}, \mathrm{Mg}$, and $\mathrm{Ni}$ (and also $\mathrm{Cr}$ ), results using $0.5-2$ mol L ${ }^{-1} \mathrm{HNO}_{3}$ were lower than those obtained using moreconcentrated solutions. For these elements, at least $5 \mathrm{~mol} \mathrm{~L}^{-1}$ was necessary to ensure agreement with NAA data (better than 95\%) and with no further improvement at higher concentration (7, 10, or $14 \mathrm{~mol} \mathrm{~L}{ }^{-1}$ ). Therefore, $5 \mathrm{~mol} \mathrm{~L}^{-1} \mathrm{HNO}_{3}$ was selected as the absorber solution for the proposed MIC method, yielding clear digests free of visible particles.

Determination of Fluoride in MIC Digests. Digests containing high concentrations of fluorine increase the risk of attack of quartz or glass surfaces of the digestion vessels and nebullization system components of the ICP-MS and ICP-OES instrumentation. Sample 3 (FEP) served as an arbitrarily selected sample for evaluation of the free fluoride content in the digests. Based on digestion of $400 \mathrm{mg}$ of sample and dilution to $30 \mathrm{~mL}$, the resulting $\mathrm{F}^{-}$concentration was $\sim 4500 \mathrm{mg} \mathrm{L}^{-1}$, corresponding to $\sim 45 \%$ of the fluorine originally present in the FEP sample. Despite the relatively high concentration of $F$, no damage to the quartz holder or quartz tube was observed after 80 MIC digestion cycles. Moreover, even after the analysis of $\sim 200$ digests by the proposed method, no damage to the nebullizer system was evident. These findings are in agreement with those of earlier work describing a combustion system operating at $600{ }^{\circ} \mathrm{C}$ for analysis of fluoropolymers. ${ }^{12}$ Silicon fluoride, $\mathrm{SiF}_{4}$ and $\mathrm{SiF}_{3}$, were determined by gas chromatography to be the major species; evidently, the majority of the fluoropolymer matrix is volatilized as either $\mathrm{CF}_{3}$ or $\mathrm{CF}_{2}$ during combustion. $^{12}$

Evaluation of MIC Digestion Efficiency. The RCC was used to evaluate the combustion/oxidation efficiency of the 
procedure. When combined with the reflux step, RCC values of $<1 \%$ were obtained after decomposition of all fluoropolymer samples. It is well-known that fluoropolymers (especially PTFE) are noncombustible at atmospheric pressure, even at high temperatures. However, the low RCC values confirm the high efficiency of oxidation of fluoropolymer samples and arise due to the high temperature reached (more than $1000{ }^{\circ} \mathrm{C}$ ) during combustion. Combustion of PTFE and other fluorinated polymers evaluated in this study was possible only because the pressurized system sustained a relatively high oxygen pressure (20 bar).

Analysis of Samples. The proposed method was applied to digestion of fluoropolymer samples using $5 \mathrm{~mol} \mathrm{~L}^{-1} \mathrm{HNO}_{3}$ as the absorber solution. Results for trace element analysis obtained for samples 1, 2, and 3 using ICP-MS and ICP-OES and their comparison with values obtained using NAA are shown in Table 2. For samples 2 and 3, NAA results were not available. Accuracy was evaluated by comparison of NAA and MIC results; agreement ranges from $99 \%$ to $107 \%$. Silver, cadmium, and cobalt were not detected in any of the investigated samples. Calcium, chromium, and potassium were found at high concentrations in all fluoropolymer samples (with the exception of chromium in sample 2). These data are in accord with values found in the literature on polymers. ${ }^{30}$

The LODs obtained for all trace elements by ICP-MS after MIC are indicated in parentheses (values in $\mathrm{ng} \mathrm{g}^{-1}$; determination of $\mathrm{Ca}, \mathrm{Fe}, \mathrm{K}$, and $\mathrm{Mg}$ by ICP-OES): $\mathrm{Ag}$ (10), $\mathrm{Ca}$ (75), Cd (10), Co (10), Cr (15), Cu (15), Fe (75), K (75), $\mathrm{Mg}$ (75), Mn (15), and $\mathrm{Ni}$ (15). LODs obtained following MIC were always better than those obtained by NAA. The relative standard deviation (RSD) for all results was lower than $16 \%$ for samples 1 and 3. However, for sample 2, the RSD was higher, up to $29 \%$, likely a reflection of the low concentration of the analyte $(\mathrm{Cr}, \mathrm{RSD}=28 \%)$ or poorer homogeneity of this sample $(\mathrm{Fe}, \mathrm{RSD}=21 \%$ and $\mathrm{K}, \mathrm{RSD}=29 \%)$.

\section{CONCLUSIONS}

The microwave-induced combustion (MIC) methodology developed herein is suitable for rapid and complete digestion of fluoropolymers for subsequent determination of their trace element content by ICP-MS and ICP-OES. Suitable results for all analytes are achieved using $5 \mathrm{~mol} \mathrm{~L}^{-1} \mathrm{HNO}_{3}$ as an absorber solution. In this regard, MIC avoids use of concentrated acids, significantly reducing laboratory waste and possible interferences in the analytical step. This approach allows combustion of relatively high sample masses $(400 \mathrm{mg}$ ) without exceeding the maximum operating pressure for the system ( 80 bar), thereby combining efficacy, safety (using a dedicated microwave oven fitted with pressure and temperature feedback controls), and relatively high sample throughput, since up to eight samples can be treated within $25 \mathrm{~min}$. The limits od detection (LODs) obtained with ICP-MS detection are superior to those available by NAA and the low levels of residual carbon content render the process favorable for use with other detection techniques.

\section{AUTHOR INFORMATION}

\section{Corresponding Author}

*E-mail: ericommf@gmail.com.

\section{Notes}

The authors declare no competing financial interest.

\section{ACKNOWLEDGMENTS}

The authors are grateful to CNPq, FINEP, CAPES, and NRCC for supporting this study.

\section{REFERENCES}

(1) Akovali, G. Plastics, Rubber and Health; Smithers Rapra Technology Limited: Shawbury, Shrewsbury, Shropshire, U.K., 2007; pp 58-65.

(2) Drobny, J. G. Technology of Fluoropolymers; CRC Press: Boca Raton, FL, 2009; pp 1-5.

(3) Perepelkin, K. E. Fibre Chem. 2004, 36, 43-58.

(4) Goodman, J.; Mudrak, L. Solid State Technol. 1988, 31, 37-39.

(5) Moody, J. R. J. Cryst. Growth 1988, 89, 43-48.

(6) Resano, M.; García-Ruiz, E.; Vanhaecke, F. Spectrochim. Acta, Part B 2005, 60, 1472-1481.

(7) Resano, M.; Verstraete, M.; Vanhaecke, F.; Moens, L.; Van Alphen, A.; Denoyerc, E. R. J. Anal. Atom. Spectrom. 2000, 15, 389395.

(8) Li, P.-C.; Jiang, S.-J. Anal. Bioanal. Chem. 2006, 385, 1092-1097.

(9) Karin, R. W.; Buono, J. A.; Fasching, J. L. Anal. Chem. 1975, 47, 2296-2299.

(10) Gretzinger, K.; Kotz, L.; Tschöpel, P.; Tölg, G. Talanta 1982, 29, 1011-1018.

(11) Takeuti, T.; Suzuki, M. Kogyo Kagaku 1962, 65, 1028-1032.

(12) Takenaka, M.; Yamada, Y.; Hayashi, M.; Endo, H. Anal. Chim. Acta 1996, 336, 151-156.

(13) Resano, M.; Aramendía, M.; Devos, W.; Vanhaecke, F. J. Anal. Atom. Spectrom. 2006, 21, 891-898.

(14) Mester, Z.; Sturgeon, R. Sample Preparation for Trace Element Analysis; Vol. XLI, Elsevier: Amsterdam, The Netherlands, 2003; 1286 p.

(15) Raptis, S. E.; Knapp, G.; Schalk, A. P. Frezenius Z. Anal. Chem. 1983, 316, 482-487.

(16) Flores, E. M. M.; Barin, J. S.; Mesko, M. F.; Knapp, G. Spectrochim. Acta Part B 2007, 62, 1051-1064.

(17) Flores, E. M. M.; Barin, J. S.; Paniz, J. N. G.; Medeiros, J. A.; Knapp, G. Anal. Chem. 2004, 76, 3525-3529.

(18) Pereira, J. S. F.; Knorr, C. L.; Pereira, L. S. F.; Moraes, D. P.; Paniz, J. N. G.; Flores, E. M. M.; Knapp, G. J. Anal. Atom. Spectrom. 2011, 26, 1849-1857.

(19) Antes, F. G.; Duarte, F. A; Mesko, M. F.; Nunes, M. A. G.; Pereira, V. A.; Muller, E. I.; Dressler, V. L.; Flores, E. M. M. Talanta 2010, 83, 364-369.

(20) Pereira, J. S. F.; Moraes, D. P.; Antes, F. G.; Diehl, L. O.; Santos, M. F. P.; Guimaraes, R. C. L.; Fonseca, T. C. O.; Dressler, V. L.; Flores, Erico, M. M. Microchem. J. 2010, 96, 4-11.

(21) Moraes, D. P.; Pereira, J. S. F.; Diehl, L. O.; Mesko, M. F.; Dressler, V. L.; Paniz, J. N. G.; Knapp, G.; Flores, E. M. M. Anal. Bioanal. Chem. 2010, 397, 563-570.

(22) Pereira, J. S. F.; Antes, F. G.; Diehl, L. O.; Knorr, C. L.; Mortari, S. R.; Dressler, V. L.; Flores, E. M. M. J. Anal. Atom. Spectrom. 2010, 25, 1268-1274.

(23) Mortari, S. R.; Cocco, C. R.; Bartz, F. R; Dresssler, V. L.; Flores, E. M. M. Anal. Chem. 2010, 82, 4298-4303.

(24) Flores, E. M. M.; Mesko, M. F.; Moraes, D. P.; Pereira, J. S. F.; Mello, P. A.; Barin, J. S.; Knapp, G. Anal. Chem. 2008, 80, 1865-1870.

(25) Moraes, D. P.; Mesko, M. F.; Mello, P. A.; Paniz, J. N. G.; Dressler, V. L.; Knapp, G.; Flores, E. M. M. Spectrochim. Acta B 2007, 62, 1065-1071.

(26) Muller, A. L. H.; Mello, P. A.; Mesko, M. F.; Duarte, F. A.; Dressler, V. L.; Muller, E. I.; Flores, E. M. M. J. Anal. Atom. Spectrom. 2012, 27, 1889-1894.

(27) Muller, A. L. H.; Bizzi, C. A.; Pereira, J. S. F.; Mesko, M. F.; Moraes, D. P.; Flores, E. M. M.; Muller, E. I. J. Braz. Chem. Soc. 2011, $22,1649-1655$

(28) Muller, A. L. H.; Muller, C. C.; Lyra, F.; Mello, P. A.; Mesko, M. F.; Muller, E. I.; Flores, E. M. M. Food Anal. Methods 2012, DOI: 10.1007/s12161-012-9381-y. 
(29) Dressler, V. L.; Pozebon, D.; Flores, E. L. M.; Paniz, J. N. G.; Flores, E. M. M. J. Braz. Chem. Soc. 2003, 2, 334-338.

(30) Moody, J. R.; Lindstrom, R. M. Anal. Chem. 1977, 49, 22642267.

(31) Ebnesajjad, S.; Khaladkar, P. R. Fluoropolymers Applications in Chemical Processing Industries: The Definitive User's Guide and Databook; William Andrew, Inc.: Norwich, CT, 2005; pp 217-219.

(32) Ebnesajjad, S.; Morgan, R. A. Fluoropolymer Additives; Elsevier, Oxford, U.K., 2012; pp 60-62. 